\title{
Per a què estem a STEM? Un intent de definir l'alfabetització STEM per a tothom i amb valors.
}

\author{
Digna Couso (digna.couso@uab.cat) CRECIM. Universitat Autònoma de Barcelona
}

L'educació STEM és una proposta emergent sobre la que se'n parla molt darrerament. Entre els investigadors/es, docents, educadors/es o dissenyadors/es en educació STEM no hi ha, però, gaire consens més enllà de reconèixer la necessitat d'incidir en aquest àmbit d'una forma innovadora. Així, hom pot trobar moltes maneres diferents d'entendre què ha de ser $i$ com s'ha de fer l'educació STEM. En aquest article reclamen, però, que per començar a parlar del què i el com de l'educació STEM primer hauríem de consensuar per a què o amb quin objectiu ens embarquem en aquesta demandant proposta educativa. Per fer-ho, plantegem un primer intent de definició d'alfabetització STEM en la que les competències específiques i transversals d'alt nivell així com els valors agafen protagonisme davant d'aspectes tecnològics, estètics o d'interdisciplinarietat comuns en les activitats STEM habituals.

Paraules clau: STEM, Pràctica científica, Competències transversals, Alfabetització, Equitat

STEM education is an emergent approach with a lot of presence in the current educational arena. Further than the need to have an impact in the STEM education field in an innovative way, however, there is not enough agreement among STEM education researchers, teachers, educators and/or designers. As a consequence, there are a lot of different ways to conceive both what to do and how to do it in STEM education. Our standing point in this paper is to signal the need to agree on the purpose to enrol in the demanding STEM educational approach before discussing the what's and how's of STEM education. To do so, we start by sharing a first initial attempt to define STEM literacy for all, in which the specific and highorder transversal competences and values of STEM education are more emphasised than technological, aesthetic or interdisciplinary aspects which are, on the other hand, quite common in STEM education activities.

Keywords: STEM, Scientific Practice, Transversal Competence, Literacy, Equity

\section{SABEM PER A QUĖ ESTEM A STEM?}

L'acrònim STEM (Ciència, Tecnologia, Enginyeria i Matemàtiques, per les seves sigles en anglès) [1] està cada cop més present en la realitat educativa actual. El llançament enguany del Pla STEMCat a Catalunya és només una mostra local de la preocupació internacional per l'àmbit científic-tecnològic en el seu sentit més ampli. A Europa aquesta preocupació es va posar de manifest amb la publicació de l'informe "Europe needs more Scientists" a l'inici del segle XXI, mentre que a EEUU té una antiga tradició, iniciada en l'era post-Sputnik amb l'acrònim
SMET i que avui dia viu ha ressorgit amb força. "Som la generació STEM" (Zollman, 2012).

Tant als EEUU com aquí, la principal raó de l'interès governamental, empresarial i social per l'educació STEM és la millora de la quantitat, i més recentment també de la qualitat i diversitat, dels professionals STEM, que es considera imprescindible per garantir el progrés econòmic i social desitjable. Així, en la diversitat de programes, informes i propostes vinculades al moviment STEM es poden trobar preocupacions anàlogues, que Zollman resumeix en: problemes per garantir la oferta de professionals STEM, problemes per garantir coneixement 
i innovació de tots els treballadors del futur en un món tecnificat i allò que les escoles (i també altres agents educatius no formals) "han de fer" per solucionar aquests dos problemes. En segon terme queda, en aquests documents i programes, la necessitat d'alfabetització ciutadana en l'àmbit científic-tecnològic.

Des de la nostra perspectiva d'investigadores, formadores i docents en educació científic-tecnològica i matemàtica amb una postura crítica, l'interès per l'educació STEM es centra precisament en promoure l'alfabetització en l'àmbit STEM per a tot l'alumnat com un valor personal en sí mateix. Com a futurs ciutadans d'una societat democràtica i enfrontada a grans reptes (p.ex els Objectius de Desenvolupament Sostenible de la ONU), on la ciència i la tecnologia tenen un paper protagònic tant del costat de les causes com del de les solucions, necessitem que tot l'alumnat desenvolupi una mínima competència en l’àmbit científic-tecnològic per tenir-hi alguna cosa a dir. I això de forma totalment independentment de sí formaran part del món professional STEM del futur o si seran professionals de qualsevol altre cosa on la ciència i la tecnologia tinguin un paper destacat. Primer, perquè de fet no sabem com serà el món del futur, i tenim avui dia ja sobre la taula propostes com la del decreixement controlat que auguren i imaginen un futur ben diferent de l'actual. Segon, perquè sigui com sigui el món del futur, tenim clar que un irrenunciable del mateix és la voluntat democràtica de decidir-ho entre tots, i això inclou les decisions en l'àmbit STEM des d'una perspectiva RRI o de Recerca e Innovació Socialment Responsables. Per tant, la importància d'estar alfabetitzats en l'àmbit STEM té més a veure amb la capacitació i apoderament que permeti la utilització i participació activa, responsable i critica, amb coneixement STEM, en el món que vulguem construir que no pas la preparació per contribuir a crear un món particular on la ciència i la tecnologia tingui un paper preponderant.

Aquest objectiu, però, no el considerem contraposat a l'objectiu d'aconseguir més, millors 0 , des d'una perspectiva d'equitat i gènere que ens sembla especialment adient, altres professionals en l'àmbit STEM. El motiu és que l'educació per alfabetitzar en STEM pot, explícita o implícitament, des de limitar fins a promocionar les aspiracions professionals en aquest àmbit. Avui dia, la manca d'aspiracions professionals en STEM per part d'un tipus d'alumnat és una realitat. En el nostre context, com arreu, el gènere i el nivell socio-econòmic es relacionen amb percepció de baixa capacitat en STEM i conflictes d'identificació amb els professionals d'aquest àmbit (EVERIS 2012). Com a conseqüència, les nostres alumnes i també aquell alumnat de nivell socio-econòmic baix tenen baixes aspiracions pel món professional STEM, en particular en certes branques del mateix. I tenen aquestes aspiracions baixes per les raons equivocades: que no creuen que hi valguin $i$ que no s'hi veuen. L'alfabetització en l'àmbit STEM amb perspectiva de gènere i equitat hauria de possibilitar un empoderament i superació d'estereotips que permeti aquestes aspiracions sense necessàriament promocionar-les. Es tracta de que tots els nostres alumnes siguin ciutadans alfabetitzats en STEM i puguin ser, si així ho desitgen, professionals apoderats en aquest àmbit o d'altres relacionats. Aconseguir-ho seria una situació avantatjosa per tothom, ja que no només garantiria un accés al món professional STEM més just, sinó sobretot una ciutadania més apoderada i implicada així com també uns professionals STEM més diversos que reportarien beneficis socials i econòmics.

Per decidir quina educació STEM és la més adient per aconseguir-ho, però, cal primer aclarir quina és aquesta alfabetització o competència ciutadana en l'àmbit STEM que possibilita aspiracions professionals en el mateix per a tots i totes les alumnes. Es a dir, cal operativitzar i definir aquesta competència de forma que permeti la pressa de decisions alhora de jutjar l'avinentesa i qualitat de les propostes d'educació STEM disponibles. La gran varietat de programes, entitats, activitats i projectes STEM que hom pot trobar a la xarxa i també en el nostre entorn fa pensar que potser no totes aquestes propostes, professionals i entitats persegueixen els mateixos objectius ni tenen la mateixa idea del que vol dir estar alfabetitzat en aquest àmbit. I, de fet, els pocs intents de definició no han aconseguit un mínim acord per concretar què és l'alfabetització STEM.

La literatura educativa tampoc ofereix gaire ajut, mes enllà de reconèixer que STEM ha esdevingut una paraula de moda buida de significat ("buzz word") degut a la seva polisèmia. En general, es troben molts més articles centrats en discutir què és 0 no educació STEM, i com s'ha de portar a terme, que no pas quin hauria de ser el resultat en les capacitats i coneixements dels alumnes amb aquesta proposta educativa. I en els pocs documents i articles dedicats a parlar d'alfabetització STEM, la majora de les definicions es realitzen des d'una visió que té en compte les necessitats socials i econòmiques, però que "passen per alt les necessitats personals" (Zollman 2012). Es a dir, sembla que no tenim clar què volem aconseguir, en termes de competència ciutadana, a l'optar per l'educació STEM.

En aquest article volem fer un primer intent, a partir del que ja sabem sobretot d'educació científica, però també matemàtica i tecnològica, de definició de competència i alfabetització STEM per a tothom. En fer-ho, volem discutir les implicacions d'aquesta tria, diferenciant els irrenunciables (allò que no hauríem de perdre) d'altres aspectes que poden variar segons quins altres sub-objectius educatius més enllà de l'alfabetització es persegueixin. En 
fer-ho creiem que contribuïm a la important discussió existent sobre què és i com ha de ser l'educació STEM, des del posicionament que per aportar en aquesta discussió hem d'acordar primer per a què la volem, l'educació STEM.

\section{COMPETÈNCIA O ALFABETITZACIÓ STEM: DE QUĖ ESTARÍEM PARLANT?}

Tot i que no hi ha gaires definicions acadèmiques d'alfabetització STEM, hom pot trobar entre les propostes, entitats i programes de promoció de l'educació STEM, tan a nivell formal com informal, diferents referències a aquest concepte. En general, les referències a l'alfabetització STEM destaquen dos aspectes clau: el fet de que s'utilitzen conceptes de les disciplines implicades (ciència, tecnologia, enginyeria i matemàtiques) i el fet que això és fa per comprendre i solucionar problemes (Zollman 2012). $O$ dit d'una altre forma, les definicions existents d'alfabetització STEM mostren la voluntat competencial de posar el coneixement de cada una de les famílies de disciplines incloses en STEM en ús. Aquesta orientació és coherent amb les definicions existents d'alfabetització o competència per a cada una de les àrees disciplinaries d'STEM. Per exemple, en el nostre currículum actual o en el marc avaluatiu de PISA la competència científic-tecnològica es redacta en termes similars.

A aquesta definició bàsica alguns autors afegeixen dos trets que semblen diferencials de les propostes STEM: la integració de conceptes de les diferents disciplines involucrades en STEM i el foment de la innovació o creativitat. Un exemple és la definició de Balka: "l'alfabetització STEM és l'habilitat d'identificar, aplicar e integrar conceptes de la ciència, la tecnologia i la matemàtica per comprendre problemes complexos i per innovar en la seva solució" (Balka, 2011, p. 7). En aquesta definició es dona importància a ser capaç d'integrar els conceptes 0 idees pròpies de las famílies disciplinàries d'STEM per posar-los en un ús en concret que implica el domini de competències transversals del segle XXI: resoldre problemes i fer-ho de forma creativa. Això implica donar un valor afegit a la proposta STEM respecte propostes competencials particulars de cada branca disciplinària en afegir necessàriament les competències transversals a les disciplinàries.

En la definició que volem aportar d'alfabetització STEM crèiem que tots aquests trets són irrenunciables: la visió competencial (el fet d'aspirar a ser capaç de posar coneixement en ús), el fet de treballar coneixements de les disciplines implicades de forma més o menys integrada i sobretot el fet d'incorporar de forma explícita les competències transversals més importants, com ara les competències del segle XXI. Trobem a faltar, però, altres aspectes que crèiem que convé incorporar en una definició més complerta d'alfabetització STEM. Aquests són, en particular: 1) Una visió dels coneixements o continguts disciplinaris que faci referència explícita als coneixements tant de com sobre les disciplines, destacant la importància dels coneixements 0 continguts no conceptuals; 2) Una inclusió de les competències transversals que inclogui també altres competències del segle XXI molt rellevants, com ara el pensament crític, la competència de treballar en equip i la de comunicar, així com la visió metacognitiva d'aprendre a aprendre i 3) Una referència explícita als valors, tant com a continguts a dominar pels alumnes com a perspectiva educativa per ensenyar i aprendre'ls. Alhora, volem que la nostre definició faci una aportació explícita a aclarir dos aspectes que s'acostumen a vincular erròniament a qualitat en educació STEM, i que són el grau d'interdisciplinarietat $i$ el fet de fer servir tecnologies punteres, generalment creatives o programables. Amb tot això, la nostra proposta concreta d'un primer intent de definició d'alfabetització STEM que inclogui aquestes idees seria:

Estar alfabetitzat en STEM és ser capaç d'identificar i aplicar, tant els coneixements clau com les formes de fer, pensar, parlar i sentir de la ciència, l'enginyeria i la matemàtica, de forma més o menys integrada, per tal de comprendre, decidir i/o actuar davant de problemes complexos i per a construir solucions creatives e innovadores, tot aprofitant les sinergies personals i les tecnologies disponibles, i de forma crítica, reflexiva i amb valors

Dins d'aquesta proposta de definició d'alfabetització STEM s'incorpora una visió concreta dels continguts o competències específiques, competències transversals així com els valors que considerem necessaris de treballar en educació STEM per garantir l'alfabetització. A continuació discutim cada un d'aquests aspectes, amb la voluntat d'aclarir una mica més per a què, crèiem, hem d'estar a STEM.

\section{Quins continguts? Idees clau i practiques STEM}

En el marc de l'educació STEM hi ha profundes discussions sobre a quines famílies disciplinàries fa referència i quines disciplines en concret s'inclouen en cada una. Aquesta discussió engloba des de quines disciplines concretes de la ciència o de la enginyeria s'inclouen (per exemple, si l'astronomia o la paleontologia es consideren STEM); si s'inclouen altres branques relacionades (per exemple, si considerem incloses les ciències mediambientals, la medicina o la farmàcia) o inclús si es tenen en compte àrees que en el nostre entorn es consideren de ciències socials, com ara la geografia, l'economia o la 
psicologia, entre altres. Quan la perspectiva educativa que es tria és STEAM, afegint una $A$ d'arts (Arts), humanitats (Liberal Arts) o fins i tot de totes les disciplines (All, per les seves sigles en anglès), s'augmenta encara més la complexitat del problema d'establir una frontera disciplinar que delimiti l'àmbit STEM. De fet, què es considera STEM depèn de què es considera ciència, enginyeria 0 matemàtiques escolars en cada context cultural i curricular. En alguns contextos s'han proposat acrònims alternatius, com ara STREAM, que inclouen disciplines tan allunyades de l'àmbit científic-tecnològic com ara la religió!.

Independentment de quines siguin les disciplines que es considerin incloses a STEM en cada context, seleccionar bé quins han de ser els continguts propis de les mateixes que s'han de treballar en l'educació STEM resulta imprescindible. Com hem vist, però, en les definicions d'alfabetització STEM sovint es fa referència als continguts de forma ambigua (coneixements) o bé fent referència únicament als continguts conceptuals (conceptes). L'anàlisi de les activitats que hom troba normalment amb l'etiqueta STEM, però, mostra un interessant contrast amb aquestes definicions, ja que en general s'inclouen activitats molt manipulatives, de caràcter observacional, indagatiu o de construcció, on els continguts de naturalesa més procedimental o tècnica tenen un clar predomini i no sembla treballar-se cap contingut conceptual en profunditat. Quins són, doncs, els continguts necessaris per estar alfabetitzat en STEM?

Avui dia considerem que no hi ha prou amb els continguts conceptuals ni tampoc amb la inclusió dels procedimentals per poder dir que estem alfabetitzats en una àrea disciplinar. Primer, perquè l'alfabetització requereix no tant un domini de continguts conceptuals d'una disciplina com un domini d'uns certs continguts en concret d'aquella disciplina, que són aquelles idees clau que defineixen la seva forma de mirar el mon i que tenen més potencial de comprensió i actuació en el nostre entorn (Couso, 2015; Harlen, 2010; NRC, 2012). En segon lloc, perquè el coneixement d'una disciplina ha de ser epistèmic, es a dir, incloure no només allò que hem aconseguit saber sinó també com ho sabem i perquè ho crèiem (Garrido \& Simarro, 2014; Grandy \& Duschl, 2007; Osborne, 2014). Per exemple, en ciències, resulta tant important conèixer un producte important de la ciència com és la teoria de l'evolució, com de quina forma es genera coneixement per arribar a proposar una teoria i perquè se sustenta la mateixa. Així, tant les pràctiques de les disciplines (les formes de fer, parlar i raonar) com els seus sistemes de valors (allò que valoren i promouen) són una part indissoluble del coneixement de les mateixes: de fet són aquells coneixements que els hi donen sentit perquè permeten diferenciar-les i triar quina és més rellevant per cada situació o problema en concret.

Aquesta forma d'entendre els continguts disciplinaris no com una llista de conceptes o tècniques, sinó com una forma de fer, pensar, parlar, sentir i valorar pròpies d'una comunitat de pràctica concreta (per exemple la científica) és la base de la nova reforma curricular als EEUU, on el currículum s'organitza en idees clau, pràctiques socio-discursives $\mathrm{i}$ nocions meta-disciplinaries pròpies de cada àmbit disciplinar (NSF 2012). La idea és desplaçar el focus de l'educació científica i enginyeril dels productes de la ciència i la tecnologia (tot allò que sabem, per exemple fets, nomenclatura, lleis,...) fins a què és el més important que sabem (les idees clau) i com ho sabem i perquè ho crèiem (les pràctiques epistèmiques) (NRC, 2007). En ciències aquestes pràctiques inclouen l'elaboració de preguntes investigables 0 l'elaboració de conclusions en base a proves. En el nostre context, la proposta de l'Activitat Científica Escolar de Izquierdo i seguidors fa més de dues dècades que promulga les mateixes idees (Izquierdo, Espinet, García, Pujol, \& Sanmartí, 1999), fomentant propostes curriculars contextualitzades i competencials on els alumnes treballen models clau de les ciències (les idees més importants que ha generat la ciència) tot involucrant-se en les pràctiques d'indagar, argumentar i sobretot modelitzar (veure Projecte Competència Científica 12-15). Referències similars per a l'enginyeria o la matemàtica poden trobar-se en diferents currículums i informes arreu, on es destaca que allò crucial en aquestes disciplines no és un concepte concret com ara el d'engranatge o una tècnica concreta com ara sumar fraccions, sinó les pràctiques pròpies d'aquestes disciplines: per exemple optimitzar, pensar sistèmicament o visualitzar en el cas de l'enginyeria o raonar abstractament i buscar patrons en el de la matemàtica. Tot i que no disposem avui dia d'un llistat consensuat d'aquestes pràctiques per a l'àmbit STEM que hom pugui utilitzar directament, la idea d'anar més enllà dels continguts conceptuals i involucrar els epistèmics considerem que és irrenunciable i que hauria d'afegir-se explícitament en una definició d'alfabetització STEM.

D'altra banda, i respecte a la capacitat d'integració o interdisciplinarietat que s'ha d'esperar o no en alfabetització STEM, la proposta d'entendre STEM com un àmbit en el que desenvolupar les formes de raonar, fer, parlar, sentir i valorar de l'àmbit científico-tecnològic ajuda a posicionar-se en una postura d'integració gens radical. Si bé un cert grau d'integració és desitjable i es pot aconseguir, les pràctiques de la ciència, l'enginyeria i la matemàtica són 
diferents ontològicament i epistemològica, i com a conseqüència difícilment es podran treballar totes alhora en profunditat. De fet, de vegades és impossible fer-ho perquè el que és un valor en un àmbit pot ser un anti-valor en l'altre. Per exemple, idealitzar a ciències vs realitzar a enginyeria, o demostrar a matemàtiques vs comprovar hipòtesis a ciències. En aquest sentit, estar alfabetitzat en STEM no hauria d'entendres tan com ser capaç de participar en les pràctiques de la ciència, l'enginyeria i la matemàtica a la vegada, sinó com saber navegar entre elles amb comoditat, sent capaç de participar-hi amb sentit i de decidir quina s'ha de prioritzar en cada moment per resoldre un problema real. Per exemple, reconèixer que per a saber perquè un vaixell qualsevol sura ens cal aprofundir en la pràctica científica de modelitzar la flotació, però que per a construir un vaixell en concret o testejar quins suren millor allò més adient serà seguir les fases del procés tecnològic (pràctica enginyeril). I reconèixer que, en fer-ho, puc estar aplicant conceptes científics, tecnològics 0 matemàtics adients (i d'aquí el cert grau d'integració) però que la pràctica, es a dir el discurs i forma de fer i mirar que desenvolupo, serà generalment d'una d'aquestes branques disciplinàries en cada moment.

\section{Quines competències transversals? Aquelles no tan transversals}

En les propostes de definició de competència STEM, com hem vist, s'inclouen de manera explícita algunes competències transversals, com ara la resolució de problemes i la creativitat. Aquestes, però, no són totes les competències transversals que la literatura ha senyalat com a importants en el moment actual. Ens cal analitzar, per tant, les diferents propostes de competències transversals per decidir quines són clau per a complementar les competències disciplinàries a l'àmbit STEM. A més, algunes d'aquestes competències transversals en realitat coincideixen amb competències disciplinàries d'STEM que tenen significats diferents per les diferents disciplines d'STEM. En aquest sentit, cal discutir el paper de les competències transversals en una alfabetització STEM.

Des de l'inici del moviment educatiu competencial s'han proposat diferents conjunts de competències bàsiques per a la ciutadania, diferenciant entre disciplinàries 0 associades a àmbits de coneixement específics de les que tenen un caràcter transversal. Aquestes competències transversals s'inspiren en gran mesura en les HOTS o habilitats de pensament d'ordre superior, definides com els nivells més avançats de pensament en els que ens podem involucrar. Per exemple, en les reformulacions actuals de la coneguda taxonomia de Bloom serien el pensament crític, la capacitat d'anàlisi i l'avaluació. A més a més, en els darrers anys, altres habilitats i disposicions de caràcter horitzontal han estat també reivindicades social i sobretot empresarialment, estenentse l'ús del terme "soft skills" per aglutinar aquelles habilitats interpersonals o socials que, tot i no semblar cognitivament demandants, resulten imprescindibles pel bon desenvolupament personal, social i laboral de la persona i no sempre es desenvolupen adientment. En son exemples el treball en equip o la capacitat de comunicació.

Les formulacions recents de les competències transversals engloben aquestes nocions clàssiques de HOTS i soft skills, i afegeixen altres aspectes per tenir en compte les demandes de la dinàmica, global i profundament digital societat actual. En aquest sentit, les competències del segle XXI es proposen com un "kit de supervivència" de competències transversals que els ciutadans han de dominar per sobreviure en el segle que els ha tocat viure. Aquestes habilitats inclouen el mencionat pensament crític i la resolució de problemes, però també la col-laboració i el lideratge, l'agilitat i adaptabilitat, la iniciativa, la capacitat de comunicació efectiva, l'accés i anàlisis de la informació i la curiositat e imaginació (Wagner 2003). Posteriors classificacions i reformulacions d'aquestes competències del segle XXI, en particular la coneguda proposta del Partenariat P21, han incorporat explícitament l'alfabetització digital i mediàtica, i separat les habilitats per a la vida personal i laboral de les destreses per aprendre i innovar. Aquestes darreres, conegudes com les $4 \mathrm{Cs}$ per les seves sigles en anglès, inclouen les mencionades pensament crític i resolució de problemes, comunicació, treball en equip i creativitat. Aquestes quatre competències transversals del segle XXI són les més citades en les propostes STEM.

Independentment de si només s'han de considerar les $4 \mathrm{Cs}$ com a competències transversals necessàries per l'alfabetització STEM o bé si s'hi ha d'afegir alguna altra competència o habilitat transversal més, allò que ha generat més controvèrsia a la literatura tant d'STEM com en general ha estat la consideració o no de les mateixes com a objectiu d'aprenentatge per se. Es a dir, si aquestes competències transversals es poden aprendre fora de les disciplines i transferir-se directament d'un domini a un altre. La literatura cognitiva sembla indicar que coneixement i destreses són interdependents, i que una base de coneixement disciplinari és imprescindible per desenvolupar importants competències transversals (NRC, 2007). En resolució de problemes, per exemple, un meta-anàlisis de 40 experiments investigant formes d'ensenyar resolució de problemes 
científics va trobar que les estratègies més efectives van ser aquelles en les que es treballava el coneixement implicat (per exemple incloent activitats com mapes conceptuals) per davant d'altres enfocades exclusivament en estratègies generals de resolució de problemes (Taconis et al, 2001). El mateix passa amb el pensament critic, que es considera fortament depenent del coneixement del tema que es tracti $\mathrm{i}$ que, tot i millorar amb la pràctica, no és una habilitat que es pugui aprendre i, un cop apresa, aplicar en qualsevol altre situació (Willingham, 2008). I d'igual forma passa amb la creativitat, tot i que aquest tema és més controvertit (Plucker, 1998). De fet, és fàcil reconèixer que no és el mateix ser crític en ciències que en enginyeria, ni resoldre problemes tecnològics que matemàtics, ni ser creatiu en ciències que en arts. A pesar de que totes les disciplines STEM inclouen l'argumentació entre les seves competències, què compta com a evidència i les regles d'una bona argumentació depenen profundament de l'àmbit disciplinari (NRC 2012).

Aquesta dependència del domini de contingut de bona part de les competències del segle XXI (en particular les destreses per aprendre i innovar) ens hauria de portar a pensar que, a pesar del nom, no són competències transversals en el sentit d'universals: 1) no tenen una definició $i$ forma d'entendres totalment independent del context d'ús ni de la mirada disciplinària i 2) no es poden desenvolupar del tot sense l'aprenentatge de continguts (idees clau i pràctiques) de cada àmbit. De fet, una forma interessant d'afrontar aquesta necessitat de noves competències adients pel segle XXI és no entendre-les com a competències transversals a desenvolupar en totes o inclús "a part" de les disciplines. Més aviat són part dels objectius d'aprenentatge disciplinaris, que s'han estès més enllà del seu enfocament tradicional i passen a ser continguts més sofisticats i de més alta demanda cognitiva, discursiva i social.

Des d'aquesta perspectiva que compartim desenvolupar les competències del segle XXI implica, de fet, augmentar la demanda competencial de cada disciplina. Això te importants implicacions a l'aula. Estem d'acord amb l'informe de Pellegrino i col-legues en que el rang de competències del segle XXI s'han de desenvolupar dins les disciplines, i que això requereix dedicar temps d'ensenyament i aprenentatge addicionals i una important varietat de recursos metodològics i didàctics (Pellegrino, Hilton, \& Learning, 2012). O dit d'una altre forma: no necessitem posar el focus en ensenyar creativitat, resolució de problemes o metacognició a més a més, en el context de o inclús enlloc d'ensenyar ciències i enginyeria. Hem d'aconseguir ensenyar ciència i enginyeria desenvolupant la creativitat, la resolució de problemes, el pensament crític, la comunicació i la metacognició, entre d'altres.

Els dos punts anteriors proposen considerar les practiques i les competències transversals com continguts propis de les disciplines STEM. Aquesta recomanació, tot i referir-se a què ensenyar, determina en part com fer-ho. Com hem defensat en altres llocs, de fet, el què i el com ensenyar no son tan independents com sembla (Couso 2014). Per exemple, no es pot aprendre a argumentar o a indagar sense participar activament en argumentacions e indagacions. A més, els dos tipus de continguts són compatibles i afavoreixen un treball conjunt. Si aconseguim que els alumnes s'involucrin en les pràctiques de la ciència i l'enginyeria escolar, que són pràctiques anàlogues a les de la ciència i l'enginyeria reals, llavors serà més fàcil desenvolupar aquestes competències del segle XXI que necessàriament formen part de la forma de fer de científics i enginyers "experts". Per exemple, si en el tema de la germinació i creixement de les plantes els alumnes desenvolupen preguntes investigables; dissenyen $\mathrm{i}$ duen a terme els seus experiments i aprenent a comunicar en un cert format els seus resultats, això els serveix, alhora: 1) per desenvolupar la seva creativitat científica i capacitat comunicativa en ciències; 2 ) el seu coneixement competencial de ciència (aplicar i avançar en el que saben de plantes, de germinació, etc) i 3) el seu coneixement competencial sobre ciència (aplicar i avançar en el que saben sobre què és indagar, com indaguem, quan és vàlida una indagació,...). Si ho fan el en context de crear un jardí vertical que doni la benvinguda a la seva escola, també treballaran la seva creativitat artística en la fase de disseny i fins i tot el procés tecnològic si segueixen explícita i reflexivament aquests passos per a resoldre la tasca.

\section{Quins valors? Equitat i sostenibilitat en el què, el com i el perquè}

Desenvolupar idees clau i pràctiques STEM a l'aula, i fer-ho desenvolupant alhora competències del segle XXI, es pot fer per motius molt diferents. A I'inici comentàvem que el moviment STEM ha estat iniciat i continua liderat des de la perspectiva d'aconseguir millors professionals STEM, i per tant, des d'una motivació socio-econòmica. També existeix, però, la motivació democràtica i ètica per a l'educació STEM que hem presentat $i$ argumentat en aquest article, relacionada amb el desig d'apoderament de la ciutadania en temes científic-tecnològics en un context de participació ciutadana en la recerca científica (RRI). Triar quins d'aquests objectius són el centre de cada proposta educativa STEM no està exempt, òbviament, de valors. 
Els valors a STEM, però, no es troben només en la motivació darrera el suport per aquesta proposta educativa. Dins l'enorme diversitat d'activitats i programes diferents que trobem a STEM, les diferents tipologies, formes d'organització, recursos que s'utilitzin, públic objectiu, etc. comuniquen en sí mateixos uns valors i emfatitzen el treball en altres valors. Per exemple, associar STEM (o inclús pensar que només podem fer STEM) utilitzant tecnologies creatives d'un elevat cost (com ara impressores en 3D, robots comercials o kits sofisticats per dissenyar sensors, etc) fa que les activitats STEM arribin més a un cert alumnat. Si associem STEM a activitats extra-escolars no obertes a tothom passa el mateix. Un programa STEM que engloba activitats amb materials reciclats o casolans, tecnologies programables de molt baix cost, que es fa compartint recursos amb altres entitats (ateneus de fabricació o maker spaces públics), que es fa a l'aula integrant tot l'alumnat, que es preocupa de l'impacte mediambiental que genera, s'orienta a solucionar problemàtiques locals amb impacte social i/o que es fa de forma extra-escolar en programes socials, etc. comunica i fa desenvolupar uns valors molt diferents. En són exemples que ja existeixen avui dia els espais tinkering a escoles públiques, fabricar joguines amb deixalles, participar en projectes de ciència ciutadana per investigar problemàtiques locals (com la contaminació al barri) o globals (com millorar la biodiversitat o ajudar en detecció de malalties), programar jocs sobre el consum desproporcionat o com protegir-se dels abusos infantils, desenvolupar clubs de programació en contextos socialment vulnerables, construir instruments musicals per tocar música de diferents cultures, teatralitzar el paper històric de les dones a la ciència, incorporar altres matemàtiques 0 ciències en contextos multiculturals, fer divulgació científica als barris i per altres públics als que no acostuma a arribar, etc. Tot $i$ les critiques que en part comparteixo respecte certes propostes STEM que promouen el consum irresponsable, la tecnocràcia $i$ l'elitisme hi ha tot un ventall d'activitats i programes STEM que emfatitzen els valors contraris: produir com a forma de reutilitzar i reduir; ciència i tecnologia ètica amb i per a la societat i valoració de la contribució creativa de tothom. Aquests valors, però, s'han de fer explícits per canviar la consciència col-lectiva sobre què és i què pot ser l'educació STEM. Des de la meva perspectiva, els valors de l'equitat i la sostenibilitat haurien de ser irrenunciables.

Respecte l'equitat, hem publicat en altres llocs que el posicionament STEM del nostre alumnat (com es veuen en aquest àmbit, quin paper creuen que poden tenir ells a STEM i quin paper donen a I'STEM a les seves vides) depèn de moltes variables (veure projecte STEAM4U [2]). Les més importants són la identitat respecte la identitat associada a les persones interessades o treballant a STEM, les aspiracions professionals en aquest àmbit, la capacitat que tenim i la percepció d'auto-capacitat, es a dir, com de "bons/bones" crèiem que som a STEM. Totes aquestes variables es desenvolupen en context, amb una influència important de la societat en general, i la família i l'escola en particular.

En el nostre context identitat $i$ imatge de les professions STEM reprodueixen els patrons identificats internacionalment des dels 70: les professions STEM es continuen associant a homes, blancs, de classe mitja/alta i excepcionalment brillants. També a personalitats geek: infantils, obsessives, poc comunicatives 0 asocials i profundament vocacionals. Reconciliar la pròpia identitat de, per exemple, nena femenina o nen magrebí amb la imatge socialment compartida d'STEM no és fàcil. A més, quan STEM no és familiar (quan no es reconeixen en l'entorn proper persones que gaudeixin, visquin o valorin l'àmbit STEM) les aspiracions STEM són molt baixes, i per tant la motivació cap aquest àmbit viscut com aliè encara es redueix més. Per últim, i més important, el nostre alumnat té un important problema de percepció d'autoeficàcia, amb més del $45 \%$ global (i per sobre el $55 \%$ en noies i alumnat de nivell socio-econòmic baix) convençut de que serien incapaços de seguir exitosament estudis STEM (EVERIS 2012). Això és degut a l'acumulació d'experiències negatives (treure males o simplement pitjors notes a STEM que a altres disciplines), la valoració de les seves capacitats per part dels seus referents adults, tant pares com docents o orientadors/es ("no se't dona bé,...", ) així com la imatge de dificultat excessiva associada a aquest àmbit. Treballar en la direcció de normalitzar la imatge dels professionals i persones interessades per STEM, ampliar el ventall de professions i persones que s'hi associen (comunicador/a científic/a, docent, tècnic/a, emprenedor/a, artista, traductor/a o historiador/a STEM), fer STEM més familiar (acostar STEM als barris, les famílies, etc.) i per damunt de tot, aconseguir que nens i nenes tinguin experiències d'èxit en aquest àmbit serien algunes de les estratègies a fer servir per introduir una perspectiva d'equitat $\mathrm{i}$ gènere. La didàctica de les ciències i les matemàtiques fa anys que investiga des d'una perspectiva multicultural sobre quina educació científica i matemàtica resulta més inclusiva. Serà important tenir en compte els seus resultats de forma explícita si es vol fer educació STEM amb els valors adients. Suposar que les activitats STEM, simplement per innovadores, manipulatives o acolorides, ja tenen una perspectiva d'equitat i gènere és massa simplista.

Respecte la sostenibilitat, el camp de l'educació ambiental i per a la sostenibilitat també ha treballat des de fa molts anys les diferents formes d'introduir aquesta perspectiva en totes les activitats, promovent la conscienciació, l'actuació responsable i fins i tot l'activisme. Projectes STEM d'agroecologia (per 
exemple domotitzant els horts escolars o construint recipients per eco-horts urbans), de reducció del consum energètic (per exemple realitzant auditories energètiques i campanyes actives a les escoles), de protecció de la biodiversitat local (realitzant sortides de camp vinculades a organitzacions de protecció d'espècies etc) són activitats que en el nostre context s'han anat desenvolupant en diverses escoles, generalment vinculades al moviment d'escoles verdes i a l'Agenda XXI, i que no haurien de considerarse fora d'STEM. Ans al contrari, introduir la perspectiva STEM en aquestes activitats les pot enriquir de forma important. Alhora, introduir la perspectiva ambiental a l'àmbit STEM és especialment important per tal que aquest àmbit no es converteixi en allò que els seus crítics i detractors auguren. De fet, una educació STEM sense perspectiva ambiental contribuiria als problemes i reptes als que ens enfrontem, per exemple aquells darrera els Objectius d Desenvolupament Sostenible o ODS com ara malbaratament de recursos i energia o generació de contaminació, enlloc d'aportar a les solucions.

\section{L'ALFABETITZACIÓ STEM COM A VERITABLE OBJECTIU}

Tot i que una definició mai captura tota la riquesa ideològica darrera la mateixa, ni tampoc els importants matisos que els experts de l'àmbit acostumen a donar-hi, crèiem que aquest primer intent de definició de competència STEM pot resultar d'utilitat a formadors/es, docents, educadors/es no formals i dissenyadors/es d'educació STEM. De fet, hauria de servir per començar a valorar i jutjar l'avinentesa de les diferents activitats, propostes i programes STEM disponibles avui dia. A nosaltres ens serveix per posar en quarantena les activitats d'STEM on els alumnes només manipulen objectes de l'àmbit científictecnològic amb un enfocament merament estètic, per exemple, dibuixant un quadre amb polígons 0 fent un arc de Sant Martí amb pigments. En aquestes "boniques" activitats STE(A)M generalment no s'adquireix competència en l'ús dels constructes STEM que hi ha darrera els objectes utilitzats (polígons, concentració o capilaritat), ni en cap practica STEM com ara observar, analitzar o optimitzar. I probablement tampoc en competències artístiques. També ens serveix per mostrar reserves respecte aquelles activitats típicament associades a STEM on no queden clars els valors que volem transmetre ni una perspectiva d'equitat, com ara muntar un robot comercial sense cap altre propòsit que el repte d'ensamblar-ho.

La definició que oferim no soluciona, però, tots els dubtes que hi puguin aparèixer sobre l'educació STEM. Continuarem discutint sobre si una activitat és un bon exemple d'educació STEM o no, o com fer-la per a que ho sigui. En aquesta discussió, però, és important que ens hi fixem no en allò que ens agrada de l'activitat, sinó en allò que promou i permet desenvolupar en els alumnes. Es a dir, si fent aquesta activitat el nostre alumnat està aprenent $a$ navegar amb agilitat i autonomia en l'àmbit científictecnològic, que és el nostre objectiu final. Crèiem fermament, però, que explicitar i consensuar l'objectiu últim de per a què estem a STEM (quina alfabetització és a la que diem alfabetització STEM) és un bon inici de la conversa seriosa, explícita e inapel-lable que, en educació, hem de tenir respecte l'àmbit STEM (i que, de fet, estem tenint pels passadissos). Aquest article simplement vol fer un primer pas en aquest camí, no amb la voluntat de que ens enredem en discussions sobre versions de definicions, sinó amb la finalitat que ens enredem, cabudament, en aclarir l'objectiu final dels nostres esforços en educació STEM.

\section{Agraïments}

Aquest article inclou una definició d'alfabetització STEM que l'autora ha presentat en diverses xerrades i seminaris al llarg del 2017 i 2018, i particularment al programa de formació STEM del Pla STEMCat del Govern de Catalunya. En cada presentació, la definició s'ha anat modificant i enriquint, fruit de les converses amb molts professionals de l'àmbit. Vull agrair a totes les persones que hi han aportat, amb la seva invitació, comentaris, exemples i/o preguntes. En particular vull agrair a Ana Albalat, Jordi Domènech, Victor López i especialment Cristina Simarro les converses sobre educació STEM que tant m'han influenciat.

\section{Bibliografia}

COUSO, D. (2015). La clau de tot plegat: la importància de "què" ensenyar a l'aula de ciències. Ciències.

EVERIS (2012) Factores influyentes en la elección de estudios científicos, tecnológicos y matemáticos. Disponible a: goo.gl/TBBKPj

GARRIDO, A., \& SIMARRO, C. (2014). El nou marc d'avaluació de la competència científica PISA 2015: Revisió i reflexions didàctiques. Ciències, 28, 21-26.

GRANDY, R., \& DUSCHL, R. A. (2007). Reconsidering the Character and Role of Inquiry in School Science: Analysis of a Conference. Science \& Education, 16(2), 141166.

HARLEN, W. (2010). Principles and big ideas of 
science education. Gosport, Hants, UK.

IZQUIERDO, M., ESPINET, M., GARCÍA, M. P., PUJOL, R. M., \& SANMARTÍ, N. (1999). Caracterización y fundamentación de la ciencia escolar. Enseñanza de Las Ciencias.

NRC. (2007). Taking Science to School: Learning and Teaching Science in Grades K-8. Board on Science Education, Center for Education. Division of Behavioral and Social Sciences and Education. Washington, D.C.: The National Academies Press.

NRC. (2012). A framework for K-12 Science Education. Practices, Crosscutting Concepts and Core Ideas. Washington, D.C.: The National Academies Press.

OSBORNE, J. (2014). Teaching Scientific Practices: Meeting the Challenge of Change. Journal of Science Teacher Education, 25(2), 177-196.

PELLEGRINO, J. W., HILTON, M. L., \& LEARNING, D. (2012). Education for Life and Work. https://doi.org/10.17226/13398

PLUCKER, J. A. (1998). Beware of Simple Conclusions: The Case for Content Generality of Creativity. Creativity Research Journal,
11(2),

$179-182$.

https://doi.org/10.1207/s15326934crj1102_8

TACONIS, R., FERGUSON-HESSLER, M.G.M. \& BROEKKAMP, H., (2001). "Teaching science problem solving: An overview of experimental work," Journal of Research in Science Teaching, 38(4), 442- 468

ZOLLMAN, A. (2012). Learning for STEM literacy: STEM literacy for learning. School Science and Mathematics, 112(1), 12-19.

WAGNER, T. (2008). The global achievement gap: Why even our best schools don't teach the new survival skills our children need - and what we can do about it. New York, NY: Basic Books

WILLINGHAM, D. T. (2008). Critical Thinking: Why Is It So Hard to Teach? Arts Education Policy Review, 109(4), 21-32. https://doi.org/10.3200/AEPR.109.4.21-32

[1] Fem servir l'acrònim STEM, en anglès, en comptes de CTIM en català per coherència amb I'ús administratiu que s'està donant a aquestes sigles en particular en el Pla STEMCat i en les formacions docents associades

[2] http://steam4u.eu/ 